Original article

\title{
Effect of flavonoid-containing extracts on the growth of transplanted sarcoma 45, peripheral blood and bone marrow condition after oral and intramuscular administration in rats
}

\author{
Nikita A. Navolokin, Dmitry A. Mudrak, Alla B. Bucharskaya, Olga V. Matveeva, Sergey A. Tychina, \\ Natalya V. Polukonova, Galina N. Maslyakova
}

Saratov State Medical University n.a. V.I. Razumovsky, Saratov, Russia

Received 26 January 2017, Revised 19 June 2017, Accepted 30 June 2017

(C) 2017, Navolokin N.A., Mudrak D.A., Bucharskaya A.B., Matveeva O.V., Tychina S.A., Polukonova N.V., Maslyakova G.N.

(C) 2017, Russian Open Medical Journal

\begin{abstract}
Objective - Discovery of the apoptosis-inducing effects of flavonoid vagonin allowed to make an assumption of existence of similar effect in others flavonoids. This study of the effects of extracts from Gratīola officinālis, Helichrýsum arenárium and diploid forms of Zea mays on bone marrow and blood leucocytes at intramuscular and oral administration was carried out on rats bearing sarcoma 45. Earlier, the apoptosis-inducing effects were detected for these extracts but the toxic effects of extracts on blood and bone marrow have not been studied. Therefore, the aim of this study was to investigate the effects of these extracts on white blood cell count and bone marrow morphology.

Material and Methods - The experiments were carried out on 48 male Wistar albino rats according to University's Animal Ethics Committee (Protocol № 13, 2011, Saratov, Russia) and the relevant national agency regulating experiments on animals. We evaluated white blood cell count and bone marrow morphology in animals after oral and intramuscular administration of extracts. A growth rate of tumor was also ranked.

Results - Oral and intramuscular administration of extracts from flavonoid-containing plants Zea mays and Gratīola officinālis causes normalization of myelocytic germ parameters in bone marrow of tumor-bearing rats and increase of lymphocyte percent in white blood cell count of blood and myelogram.

Conclusion - Absence of toxic effects and normalization of myelocytic germ parameters in bone marrow of tumor-bearing rats after oral and intramuscular administration of extracts from flavonoid-containing plants Zea mays and Gratiola officinālis allows to recommend further study of the antitumor effect of these extracts.
\end{abstract}

Keywords: flavonoids, Gratīola officinālis, Helichrýsum arenárium, Zea mays, bone marrow, blood, sarcoma 45

Cite as Navolokin NA, Mudrak DA, Bucharskaya AB, Matveeva OV, Tychina SA, Polukonova NV, Maslyakova GN. Effect of flavonoid-containing extracts on the growth of transplanted sarcoma 45, peripheral blood and bone marrow condition after oral and intramuscular administration in rats. Russian Open Medical Journal 2017; 6: e0304.

Correspondence to Nikita A. Navolokin. Address: Department of Pathological Anatomy, Saratov State Medical University n.a. V.I. Razumovsky, 112, Bolshaya Kazachya str., Saratov, 410012, Russia. E-mail: navolokin1@rambler.ru.

\section{Introduction}

Oncological diseases take one of the leading places in the structure of mortality all over the world. For a long time it was believed that bioflavonoids with a broad spectrum of pharmacological activity are not very perspective in terms of antitumor activity. In 2011 the apoptosis-inducing effect of plant flavonoid Vagonin was discovered in tumor cells [1, 2]. This discovery was important for further searching of flavonoids with antitumor activity, as well as study of mechanisms of their biological activity.

Previously, we have developed a method for producing flavonoid-containing extracts from Gratiola officinālis, Helichrýsum arenárium, and Zea mays, that allows obtaining non-toxic or slightly toxic extracts even from poisonous plants [3-6]. It is know that these extracts have antioxidant, antitumor, immunomodulatory [7-11] and antimicrobial [12-14] actions.
However, a detailed analysis of the toxicity of test flavonoidcontaining plant extracts and their effects on leukocyte formula of blood and bone marrow was still not done.

The aim of this study was to investigate the effect of intramuscular and oral administration of flavonoid-containing extracts of Gratīola officinālis, Helichrýsum arenárium and Zea mays on bone marrow and peripheral blood indicators of Wistar rats with transplanted sarcoma 45 .

\section{Material and Methods}

\section{Description of the extracts}

In this work we used extracts which have been obtained by a process of double extraction, followed by alcohol precipitation of non-polar compounds (glycosides and alkaloids, et al.) by chloroform from Gratiola officinalis plant, Helichrýsum arenárium and Zea mays [3-5]. This method has been patented by us. Herbal 
raw materials for these experiments were collected in Saratov region (Russia). Zea mays was grown on an experimental area in Saratov region, and the raw material was provided by our collaborators from Genetics Department of National Research Saratov State University (Saratov, Russia).

Standartization of flavonoid-containing extracts was performed by quercetin and rutin. Mean of quercetin in Gratiola officinalis extract was determined from a calibration curve using a standard sample of quercetin (Sigma, 98\%) and should not be less than $0.66 \%$. Quercetin in dry extractives residue $(350 \mathrm{mg}$ extractives) was defined by high performance liquid chromatography (HPLC), it should not be less than 350 micrograms.

The average value of quercetin in Helichrýsum arenárium extract was $0.3 \mathrm{mg} / \mathrm{ml}$, as determined by HPLC, and the amount of quercetin in dry residue (for $350 \mathrm{mg}$ of extractives) was 150 micrograms. The average value of rutin was $29.40 \mathrm{mg} / \mathrm{ml}$ as was found by absorption spectroscopy method. The weight percentage of flavonoids in the extract was $21.0 \%$.

Zea mays extract had an average value of quercetin $0.7 \mathrm{mg} / \mathrm{ml}$ as it was established by HPLC method, and the amount of quercetin in the dry residue (for $260 \mathrm{mg}$ of extractives) was 350 $\mathrm{mg}$. By molecular absorption spectroscopy the content of rutin was $16.46 \mathrm{mg} / \mathrm{ml}$. The weight percentage of flavonoids in the extract was 15.8 .

\section{Design of experiments}

The experiment was conducted according to "International Guiding Principles for Biomedical Research Involving Animals" [15]. 48 male albino Wistar rats weighing $152 \pm 12 \mathrm{~g}$ (data presented as mean with standard deviation) at the age of 3 months were used, which had been vaccinated subcutaneously in the region between shoulder blades with $25 \%$ cells suspension culture of sarcoma 45 in Hank's solution.

Two groups were formed as a control: control group №1 "healthy», intact animals without exposure; control group №2 animals with transplanted sarcoma 45 without exposure. Dual control was necessary to avoid developmental changes under the influence of transplanted tumor. Each group consisted of 6 animals.

The animals were divided into six experimental groups. The first two groups received the extract of Helichrysum: group №1 intramuscularly in a dosage of $1 \mathrm{~g} / \mathrm{kg}$; group №2 - orally in a dosage of $1 \mathrm{~g} / \mathrm{kg}$. The following two groups reseived Zea mays extract: group №3 - intramuscularly in a dosage of $0.32 \mathrm{~g} / \mathrm{kg}$; group №4 - orally in a dosage of $0.32 \mathrm{~g} / \mathrm{kg}$. The following two groups received Gratiola officinalis extract: group №5 intramuscularly in a dosage of $0.11 \mathrm{~g} / \mathrm{kg}$; group №6 - orally at a dosage of $0.11 \mathrm{~g} / \mathrm{kg}$.

Animals were brought into experiment in 72 hours after inoculation of the tumor (sarcoma 45). The extracts were administered orally and intramuscularly every day for two weeks. Intramuscular administration was carried out by sterile insulin syringes alternately in muscles of right and left hind paws of animals. Oral administration was performed using gastric tube. Prior to administration of the extract, a dosage of each aqueous extract for each animal was calculated from determination of animal mass. Thus, we reached a constant concentration of active agent per kilogram of body weight. The experiments were carried out on Wistar albino rats according to University's Animal Ethics Committee (Protocol №13, 2011) and the relevant national agency regulating experiments in animals.

After two weeks of the experiment the animals were withdrawn from the experiment by decapitation. Tumor volume was measured; the sampling of peripheral blood, bone marrow of the femur and tumor tissue for morphological examination was performed.

\section{The morphological examination}

The staining of blood smears was performed by standard methods. Quantitative and qualitative assessment of blood smears was performed. Counting at least 100 cells were produced in blood smear, and then the percentage of cells was calculated, and leukocytic formula was determined.

Bone marrow smears were fixed for 5 minutes with a solution latch - eosin methylene blue dye by May-Grunwald, and then stained for 20 minutes by Romanovsky stain. Counting (at least 500 cells) was carried out under high magnification (x1000), and their percentage was calculated (myelogram) [16]. The standard histological staining was used for morphological study of transplanted tumors.

\section{Statistical data processing}

Normality of parameter distribution was studied by ShapiroWilk test. Normal distribution characteristics have been found in groups. Therefore, we chose t-test Welch's t-test for parameter estimation. By this method, a difference between mean values with a probability of $95 \%$ was determined at $\mathrm{T} \geq 1.96$. All statistical analyzes were performed using the software STATISTICA 10.0 Interprise (StatSoft, USA).

\section{Results}

\section{Influence of extracts on growth of sarcoma 45}

After oral and intramuscular administration of Gratiola officinalis extract we revealed the significant reduction of tumor volume - respectively by $63 \%$ and $57.4 \%$. The significant reduction in tumor volume was noted after oral and intramuscular administration of Helichrysum extract - respectively by $70 \%$ and $64.6 \%$ (Table 1). The oral and intramuscular administration of anthocyanin Zea mays extract caused significant reduction of tumor volume (by in average of 61\%).

Development of vast areas of necrosis up to $90 \%$ of tumor section area was observed after administration of extracts, as well as atrophic and degenerative changes in the cells were observed at histological examination of the tumor. These two ways of extracts administration led to the reduction of tumor size and to the development of necrotic and degenerative processes in tumor.

Changes in blood leukocyte counts were observed in animals with transplanted tumor (control group №2) in comparison with control group №1. The significant increase of stab neutrophils and decrease of segmented neutrophils were noted in animals with transplanted tumors ( $\mathrm{T} \geq 1.96$ ) (Table 2 ).

Significant changes in blood indicators were not detected at intramuscular and peroral administration of Helichrysum extract in comparison with the second control group of animals with transplanted tumor (Table 2). 
Table 1. Tumor volume in animals with transplanted sarcoma 45 at the end of experiment (14th day) $\left(\mathrm{cm}^{3}\right)$

\begin{tabular}{|c|c|c|c|c|c|c|c|}
\hline & \multicolumn{7}{|c|}{ Groups } \\
\hline & Control & Helichrýsum, intr. & Helichrýsum, per. & Zea mays, intr. & Zea mays, per. & Gr. officinalis, intr. & Gr. officinalis, per. \\
\hline Tumor volume & $25.58 \pm 3.72$ & $7.66 \pm 1.37^{*}$ & $9.05 \pm 2.96 *$ & $9.96 \pm 1.56^{*}$ & $10.0 \pm 0.60 *$ & $9.41 \pm 1.70 *$ & $10.89 \pm 1.47^{*}$ \\
\hline
\end{tabular}

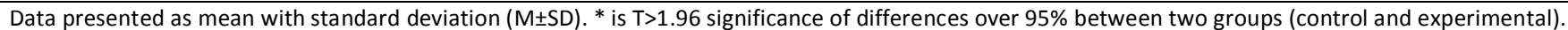
intr., intramuscular; per., peroral; Gr., Gratiola.

Table 2. Indicators of white blood cell count (\%) at administration of flavonoid-containing extracts

\begin{tabular}{|c|c|c|c|c|c|c|c|c|}
\hline \multirow[t]{2}{*}{$W B C$} & \multicolumn{8}{|c|}{ Groups } \\
\hline & Control №1 & Control №2 & Helichr., intr. & Helichr., per. & Z. mays, intr. & Z. mays, per. & Gr. offic., intr. & Gr. offic., per. \\
\hline Stab leukocytes & $1.50 \pm 0.50$ & $8.33 \pm 0.30^{A}$ & $7.67 \pm 0.30^{A}$ & $7.00 \pm 1.15^{A}$ & $13.30 \pm 1.70^{\mathrm{AB}}$ & $10.50 \pm 0.50^{\mathrm{AB}}$ & $9.66 \pm 1.20^{A}$ & $9.33 \pm 0.60^{A}$ \\
\hline Segments & $58.00 \pm 1.00$ & $11.33 \pm 0.30^{\mathrm{A}}$ & $12.67 \pm 2.10^{A}$ & $12.00 \pm 1.54^{\mathrm{A}}$ & $17.00 \pm 2.51^{\mathrm{A}}$ & $13.50 \pm 2.50^{\mathrm{A}}$ & $14.67 \pm 1.60^{A}$ & $15.67 \pm 0.80^{A B}$ \\
\hline Eosinophils & $2.00 \pm 0.50$ & $2.00 \pm 0.57$ & $1.67 \pm 0.33$ & $1.67 \pm 0.33$ & $1.33 \pm 0.33$ & $1.00 \pm 0.50$ & $1.67 \pm 0.33$ & $1.33 \pm 0.33$ \\
\hline Basophils & $0.0 \pm 0.0$ & $1.33 \pm 0.33$ & $0.67 \pm 0.33$ & $0.67 \pm 0.33$ & $0.67 \pm 0.33$ & $1.0 \pm 0.5$ & $1.0 \pm 0.33$ & $0.33 \pm 0.33$ \\
\hline Monocytes & $9.50 \pm 0.50$ & $8.00 \pm 1.54$ & $6.33 \pm 0.88$ & $8.33 \pm 0.88$ & $8.00 \pm 1.00$ & $4.00 \pm 1.00$ & $8.67 \pm 0.67$ & $5.67 \pm 0.89$ \\
\hline Lymphocytes & $29.00 \pm 1.00$ & $69.00 \pm 2.64^{\mathrm{A}}$ & $71.00 \pm 1.73^{A}$ & $70.30 \pm 1.20^{\mathrm{A}}$ & $59.00 \pm 5.17^{A}$ & $70.00 \pm 4.00^{A}$ & $64.33 \pm 3.17^{A}$ & $67.67 \pm 2.72^{\mathrm{A}}$ \\
\hline
\end{tabular}

Data presented as mean with standard deviation $(\mathrm{M} \pm \mathrm{SD})$. The significance $(\mathrm{P}<0.05)$ of differences was determined at comparing of control group №2 and all others groups (signed as ${ }^{A}$ ), and between control group №1 and experimental group №2 (Helichrýsum, peroral) (signed as ${ }^{B}$ ).

WBC, white blood cell; intr., intramuscular; per., peroral; Helichr., Helichrýsum; Z. mays, Zea mays; Gr. offic., Gratiola officinalis.

Significant increase of number of stab leukocytes by $60 \%$ and $26.5 \%$ respectively $(T \geq 1.96)$ was observed at intramuscular and peroral administration of Zea mays extract in comparison with control group №2 (Table 2).

Statistically significant increase of segmented leukocytes (by in average of 38\%) was observed at peroral administration of the extract of Gratiola officinalis in animals with transplanted tumor in comparison with control group №2 (Table 2).

\section{Bone marrow examination}

The comparative analysis of changes in the myelogram of control group showed a significant decrease - doubling of undifferentiated blasts in tumor-bearing animals in comparison with healthy animals. After peroral and intramuscular administration of extracts of Gratiola officinalis and Zea mays, the increase of undifferentiated blasts was noted in tumor-bearing animals in comparison with control group №2 and at approximation of indicators to the control values (group №1) (Table 3). Restoring of percentage of undifferentiated blasts was not observed only after administration of Helichrysum extract (orally or intramuscularly).

Myeloblasts. Significant doubled decrease of myeloblasts was observed in control group №2 in comparison with healthy animals, which may be due to influence of tumor intoxication. Analysis of myeloblasts in experimental groups showed that administration of all three extracts leads to normalization of these indicators. The most pronounced increasing of myeloblasts was after administration of Zea mays extract.

Neutrophil promyelocytes. Significant reduction of neutrophil promyelocytes was noted in tumor-bearing animals (1.4-fold in comparison with healthy animals). We have seen a further decrease of number of neutrophilic promyelocytes (2.6-fold in comparison with healthy animals) only at intramuscular administration of Helichrysum extract. A number of neutrophil promyelocytes in all other experimental groups was not reduced, and a tendency to the approximation of indicators to control values was observed.

Neutrophilic myelocytes. 2.5-fold decreasing of indicators of neutrophil myelocytes was detected in comparison with healthy animals. After oral administration of Gratiola officinalis and Helichrysum extracts, the tendency to reduce a number of neutrophils of neutrophilic myelocytes remained in tumor-bearing animals, although the obtained changes were not significant. In all other experimental groups the number of neutrophilic myelocytes was increased after administration of all extracts and reached control values of healthy animals. Significant increase of neutrophilic myelocytes 2.3 times comparison with the control group №2, but the restitution to normal indicators was noted only at oral administration of Zea mays extract. No significant changes of neutrophilic metamyelocytes and stab neutrophilic leukocytes were detected.

Segmented neutrophil leukocytes. We have observed an increase of segmented neutrophils in control group №2 in comparison with healthy animals. We have noted a tendency to decrease this type of cells in experimental groups. We observed 1.4-fold decreasing of segmented neutrophil leukocytes only at peroral administration of Helichrysum extract.

Eosinophils. A number of eosinophils in bone marrow was significantly increased - in 1.9 times in control group №2 in comparison with group of healthy animals. In accordance whith literature data, tumor intoxication may lead to increase of eosinophils in the blood [17]. It should be noted that above described changes of cell ratio in bone marrow were not accompanied by increasing of eosinophils in peripheral blood.

After administration of all types of extracts no significant changes in the proportion of eosinophilsin were observed in the experimental groups in comparison with control group №2 of tumor bearing animals. Only at peroral administration of Helichrysum extract a significant increase in the number of eosinophils was observed in comparison with control group №2 of tumor bearing animals.

Pronormoblasts. Significant reduction of pronormblasts (in 1.5 times) was observed in tumor bearing rats in comparison with healthy animals. In the experimental groups the administration of Zea mays and Gratiola officinalis extracts leads to approximation of indicators to normal values of healthy animals. Helichrysum extract did not cause changes of pronormoblasts percentage in tumor-bearing rats at both methods of administration. 
Table 3. The cellular composition (\%) at bone marrow examination

\begin{tabular}{|c|c|c|c|c|c|c|c|c|}
\hline \multirow[t]{2}{*}{ Cells } & \multicolumn{8}{|c|}{ Groups } \\
\hline & Control №1 & Control №2 & Helichr., intr. & Helichr., per. & Z. mays, intr. & Z. mays, per. & Gr. offic., intr. & Gr. offic., per. \\
\hline Undiff. blasts & $1.25 \pm 0.25$ & $0.62 \pm 0.13^{\mathrm{A}}$ & $0.50 \pm 0.00^{B}$ & $0.75 \pm 0.25^{B}$ & $1.50 \pm 0.00^{C}$ & $1.33 \pm 0.17^{\mathrm{C}}$ & $1.25 \pm 0.25$ & $1.00 \pm 0.00$ \\
\hline Myeloblasts & $1.25 \pm 0.25$ & $0.62 \pm 0.12^{A}$ & $0.83 \pm 0.33$ & $1.00 \pm 0.00$ & $1.17 \pm 0.17^{C}$ & $1.17 \pm 0.17^{C}$ & $1.00 \pm 0.00$ & $0.75 \pm 0.25$ \\
\hline Neutr. prom. & $1.75 \pm 0.25$ & $1.25 \pm 0.25^{\mathrm{A}}$ & $0.67 \pm 0.17^{B}$ & $1.50 \pm 0.50$ & $1.50 \pm 0.29$ & $1.50 \pm 0.29$ & $1.50 \pm 0.00$ & $2.00 \pm 0.00^{B}$ \\
\hline Neutr. myel. & $1.25 \pm 0.25$ & $0.50 \pm 0.00^{A}$ & $0.67 \pm 0.44^{B}$ & $0.25 \pm 0.25^{B}$ & $1.00 \pm 0.29$ & $1.17 \pm 0.17^{c}$ & $1.00 \pm 0.50$ & $0.25 \pm 0.25^{\mathrm{A}}$ \\
\hline Neutr. metam. & $1.75 \pm 1.25$ & $2.12 \pm 0.53$ & $2.00 \pm 0.87$ & $1.25 \pm 0.75$ & $2.33 \pm 0.73$ & $2.00 \pm 0.58$ & $2.00 \pm 1.00$ & $1.75 \pm 0.25$ \\
\hline Neutr. stab leyc. & $6.75 \pm 1.25$ & $6.12 \pm 0.83$ & $10.00 \pm 1.53$ & $9.25 \pm 1.25$ & $7.00 \pm 0.50$ & $6.17 \pm 0.67$ & $6.75 \pm 1.25$ & $7.00 \pm 1.00$ \\
\hline Neutr. segm. & $41.75 \pm 1.25$ & $44.87 \pm 1.65^{\mathrm{A}}$ & $37.33 \pm 5.78$ & $35.00 \pm 3.00^{\mathrm{BC}}$ & $39.50 \pm 3.62$ & $42.33 \pm 2.59$ & $36.75 \pm 6.25$ & $40.50 \pm 4.50$ \\
\hline Eosinophils & $3.00 \pm 0.00$ & $5.87 \pm 1.45^{\mathrm{A}}$ & $6.83 \pm 3.61$ & $12.75 \pm 1.75^{\mathrm{BC}}$ & $7.17 \pm 2.52^{B}$ & $5.33 \pm 1.36^{B}$ & $7.5 \pm 0.50^{C}$ & $4.50 \pm 1.50$ \\
\hline Basophils & $0.25 \pm 0.25$ & $0.75 \pm 0.32$ & $0.33 \pm 0.17$ & $0.25 \pm 0.25$ & $0.67 \pm 0.44$ & $1.00 \pm 0.76$ & 0.00 & $0.75 \pm 0.25$ \\
\hline Erythroblasts & $2.00 \pm 0.00$ & $1.62 \pm 0.31$ & $1.50 \pm 0.50$ & $1.75 \pm 0.75$ & $1.83 \pm 0.44$ & $2.00 \pm 0.00$ & $1.25 \pm 0.75$ & $2.00 \pm 0.10$ \\
\hline Pronormoblasts & $3.25 \pm 0.75$ & $2.12 \pm 0.24^{A}$ & $2.33 \pm 0.73^{B}$ & $2.00 \pm 0.50^{C}$ & $3.50 \pm 0.76$ & $4.00 \pm 1.00$ & $3.00 \pm 1.00$ & $4.00 \pm 1.00$ \\
\hline Basoph. norm. & $4.75 \pm 0.75$ & $5.87 \pm 1.01$ & $4.50 \pm 1.15$ & $5.75 \pm 0.25$ & $4.33 \pm 1.36$ & $3.67 \pm 1.09$ & $7.50 \pm 0.50$ & $4.75 \pm 1.75$ \\
\hline Polychr. norm. & $11.25 \pm 2.25$ & $9.5 \pm 1.41$ & $10.17 \pm 1.92$ & $9.00 \pm 2.00$ & $11.17 \pm 0.73$ & $14.00 \pm 1.04^{B}$ & $16.00 \pm 0.10^{B C}$ & $12.50 \pm 0.50$ \\
\hline Oxyph. norm. & $5.75 \pm 1.25$ & $6.00 \pm 0.89$ & $8.17 \pm 1.86$ & $7.50 \pm 1.50$ & $7.50 \pm 1.15$ & $6.67 \pm 0.60$ & $7.25 \pm 2.25$ & $4.50 \pm 1.00$ \\
\hline Lymphocytes & $13.75 \pm 1.75$ & $12.00 \pm 0.82$ & $13.00 \pm 1.00$ & $11.75 \pm 0.75^{\mathrm{B}}$ & $9.17 \pm 0.17^{\mathrm{BC}}$ & $8.50 \pm 0.50^{\mathrm{BC}}$ & $8.75 \pm 1.75^{\mathrm{BC}}$ & $6.25 \pm 1.25^{\mathrm{BC}}$ \\
\hline Monocytes & 0.00 & 0.00 & 0.00 & 0.00 & 0.00 & 0.00 & 0.00 & 0.00 \\
\hline Plasmocytes & $0.25 \pm 0.25$ & $0.00^{A}$ & 0.00 & $0.25 \pm 0.25$ & $0.67 \pm 0.44$ & 0.00 & $0.25 \pm 0.25$ & $0.50 \pm 0.50$ \\
\hline L/E ratio & $2.85 \pm 0.08$ & $3.08 \pm 0.35$ & $3.16 \pm 0.44$ & $3.00 \pm 0.77$ & $2.76 \pm 0.27$ & $2.30 \pm 0.05$ & $2.06 \pm 0.07^{c}$ & $2.94 \pm 0.71$ \\
\hline
\end{tabular}

Data presented as mean with standard deviation (M \pm SD). ${ }^{A}$ - The significance of differences between control groups; ${ }^{B}-$ the significance of differences between control group №1 and experimental groups; ${ }^{\mathrm{C}}$ - the significance of differences between control group №2 and experimental groups.

Undiff. Blast, undifferentiated blasts; Neutr. prom., neutrophil promyelocytes; Neutr. myel., neutrophil myelocytes; Neutr. metam., neutrophil metamyelocytes; Neutr. stab leyc., neutrophil stab leycocytes; Neutr. segm., neutrophil segments; Basoph. norm., basophilic normoblasts; Polychr. norm., polychromatic normoblasts; Oxyph. norm., oxyphilic normoblasts; L/E ratio, leukocytic-erythroblastic ratio; intr., intramuscular; per., peroral; Helichr., Helichrýsum; Z. mays, Zea mays; Gr. offic., Gratiola officinalis.

Polychromatic normoblasts (PN). The content of PN was not changed in control groups. After intramuscular administration of Gratiola officinalis extract, significant increase of PN (in 1.7 times) was noted in the experimental group in comparison with control group №2 and 1.4-fold increasing of PN - in comparison with healthy animals. In the group with oral administration of Zea mays the number of PN increased in comparison with healthy animals.

Lymphocytes. Differences of lymphocytes proportion in myelogram were not observed between control groups. A significant decrease of lymphocyte percent was noted after oral and intramuscular injection of Gratiola officinalis and Zea mays extracts.

Administration of all types of extracts had no effects on the number of neutrophilic metamyelocytes, stab neutrophils, basophils, erythroblasts, normoblasts, normoblasts, basophilic and oxyphylic normoblasts, monocytes, plasma cells (Table 3 ).

\section{Discussion}

Intramuscular and peroral administration of Helichrysum extract leads to decrease of tumor volume by $70.0 \%$ and $64.6 \%$, respectively, and does not cause changes in blood leukocyte ratio in comparison with the group of tumor-bearing rats without treatment. However, indicators in these groups are different from control values of healthy animals.

After administration of Helichrysum extract, the percentage of undifferentiated blasts, neutrophilic myelocytes, pronormoblasts in bone marrow were also similar with indicators of tumor-bearing rats without treatment. Therefore, we can assume that all changes in peripheral blood and bone marrow develop under influence of growing tumor and its secondary changes (necrosis, degeneration).

It should be noted that oral administration of Helichrysum extract normalizes the number of neutrophilic myelocyte in myelogram, and intramuscular administration of this extract reduces their fraction in myelogram in comparison with both control groups. Additionally, at oral administration of Helichrysum extract, the number of eosinophils was increased and the number of segmented neutrophils was reduced in comparison with group of tumor-bearing rats without treatment, i.e. approximation of these parameters to normal values was observed.

Regardless of administration method, Zea mays extract induces the decrease of tumor volume by $61 \%$. Increased percentage of undifferentiated blast cells, neutrophilic myeloblast and myelocytes were observed in bone marrow in animals of experimental groups in comparison with tumor-bearing rats without treatment.

These indicators approximated to control values and were not differed significantly from control group of healthy animals. Consequently, Zea mays extract itself did not affect these parameters and normalized the indicators changed due to tumor growth.

Percentage reduction of lymphocyte number in bone marrow may indicate an increased or accelerated transition to second stage of lymphocyte maturation in peripheral immunopoiesis organs. In addition, we have observed an increase of lymphocytes in peripheral blood in comparison with control values that may be the result of tumor growth and activation of specific immune processes [17, 18].

Decrease of tumor volume by $63 \%$ was note after intramuscular administration of Gratiola officinalis extract and after oral administration of the extract - by $57.4 \%$. Increase of polychromatic normoblasts (precursors of erythrocytes in the bone marrow) was noted in all animal groups (experimental and control), that can serve as an indicator of stimulating effect of extracts on erythrocyte germ. Reducing of lymphocyte number in bone marrow may also indicate an accelerated maturation of lymphocytes and their transition to second stage of maturation into peripheral organs of immunogenesis $[17,18]$. The increase of 
segmented neutrophils in peripheral blood was probably a result of tumor necrosis which develops under extract influence.

In literature there are reports of tumor growth retardation under the influence of flavonoids [19-22], however, a detailed analysis of toxicity of test flavonoid-containing plant extracts and their effects on leukocyte count in blood and bone marrow was still not done.

\section{Conclusions}

Administration of all types of extracts causes inhibition of tumor growth of transplanted tumors in a range from $61 \%$ to $70 \%$ depending on administration method and type of extract, and also causes dystrophic and necrotic changes in tumor tissue.

Tumor growth of sarcoma 45 causes changes of percentage ratio of cells in white blood cell count and myelogram.

Oral and intramuscular administration of flavonoid-containing extracts: anthocyanin Zea mays and Gratiola officinalis extracts effects positively on myelocytic germ (undifferentiated blast cells, myeloblasts and neutrophil myelocytes) with approximation of indicators to normal values, and also leads to an increase of lymphocytes in white blood cell count and myelogram. Thus, in our opinion, it is important that antitumor effect of extracts is manifested on background of immune system activation.

Helichrýsum arenárium extract leads to normalization of percentage ratio of segmented neutrophils, but does not change the quantitative ratio of cells in comparison with tumor-bearing animals without treatment for the majority of indicators.

Absence of toxic effects and normalization of myelocytic germ indicators in bone marrow of tumor-bearing rats after oral and intramuscular administration of extracts from flavonoid-containing plants Zea mays and Gratiola officinālis allow to recommend for a further study of antitumor effect of these extracts.

\section{Acknowledgments}

The work done by Nikita A. Navolokin was supported by the Russian President's Scholarship, SP-523.2016.4 (2016-2018).

Conflict of interest: none declared.

\section{References}

1. Polier G, Ding J, Konkimalla B V, Eick D, Ribeiro N, Köhler $R$, et al. Wogonin and related natural flavones are inhibitors of CDK9 that induce apoptosis in cancer cells by transcriptional suppression of $\mathrm{Mcl}-1$. Cell Death Dis 2011; 2(7): e182. https://dx.doi.org/10.1038/cddis.2011.66.

2. Wang IK, Lin-Shiau SY, Lin JK. Induction of apoptosis by apigenin and related flavonoids through cytochrome $c$ release and activation of caspase-9 and caspase-3 in leukaemia HL-60 cells. Eur J Cancer 1999; 35(10): 1517-1525. http://dx.doi.org/10.1016/S0959-8049(99)00168-9.

3. Polukonova AV, Durnova NA, Kurchatova MN, Navolokin NA. The chemical analysis and a method of producing a new From Biological active composition of Gratiola Officinalis L. Khimija Rastitel'nogo Syr'ja 2013; (4): 165-173. Russian. https://dx.doi.org/10.14258/jcprm.1304165.

4. Grinjov VS, Shirokov AA, Navolokin NA, Polukonova NV, Kurchatova MN, Durnova NA, et al. Polyphenolic compounds of a new biologically active extract from immortelle sandy flowers (Helichrysum arenarium (L.) Moench.). Russ J Bioorg Chem 2016; 42: 770-776. https://dx.doi.org/10.1134/S1068162016070086.

5. Polukonova NV, Kurchatova MN, Navolokin NA, Bucharskaja AB, Durnova NA, Maslyakova GN. A new extraction method of bioflavanoids from poisonous plant (Gratiola officinalis L.). Russ Open Med J 2014; 3: 0304. https://dx.doi.org/10.15275/rusomj.2014.0304.

6. Navolokin NA, Polukonova NV, Maslyakova GN, Bucharskaja AB, Durnova NA. Effect of extracts of Gratiola officinalis and Zea mays on the tumor and the morphology of the internal organs of rats with trasplanted liver cancer. Russ Open Med J 2012; 1: 0203. https://dx.doi.org/10.15275/rusomj.2012.0203.

7. Navolokin NA, Polukonova AV, Bibikova OA, Polukonova NV, Maslyakova GN, Bucharskaya AB. Cytomorphological changes pig embryo kidney cells in culture (SPEV-2) under the action of a medicinal extract of Gratiola officinalis L. Fundamental Research 2014; (10-7): 1369-1374. Russian. https://elibrary.ru/item.asp?id=22677246.

8. Navolokin NA, Polukonova NV, Maslyakova GN, Bucharskaya AB, Durnova NA. The morphology of internal organs and tumors in laboratory rats with transplanted liver cancer Pc-1 when administered orally flavonoid containing extracts of Gratiola Officinalis L. and Zea Mays L. Saratov J Med Sci Res 2013; 9(2): 213-220. Russian. https://elibrary.ru/item.asp?id=20203823.

9. Tkachenko N, Pravdin A, Terentjuk G, Navolokin N, Kurchatova M, Polukonova N. Inhibiton of photodynamic haemolysis by gratiola officinalis L. extract. Proc SPIE 2015; 9448: 94480P. https://dx.doi.org/10.1117/12.2179862.

10. Tkachenko NV, Bykova EV, Pravdin AB, Navolokin NA, Polukonova NV, Bucharskaja $A B$, et al. Comparison of membrane-protective activity of antioxidants quercetine and Gratiola Officinalis L. extract under conditions of photodynamic haemolysis. Proc SPIE 2016; 9917: 99170 L. https://dx.doi.org/10.1117/12.2228291.

11. Navolokin NA, Mudrak DA, Polukonova NV, Tychina SA, Korchakov NB Bucharskaya AB, Maslyakova GN. Evaluation of the antitumor and anticachexia activity of gratiola officinalis L. Extract in rats with transplanted sarcoma 45. Siberian Journal of Oncology 2016; 15(1): 3743. Russian. https://dx.doi.org/10.21294/1814-4861-2016-15-1-37-43.

12. Polukonova NV, Navolokin NA, Rajkova SV, Maslyakova GN, Bucharskaya AB, Durnovan NA, Shub GM. Anti-inflammatory, antipyretic and antimicrobial activity of flavonoid-containing extract of Gratiola officinalis I. Eksperimental'naya i Klinicheskaya Farmakologiya 2015; 78(1): 34-38. Russian. https://elibrary.ru/item.asp?id=23070045.

13. Skvorcova VV, Navolokin NA, Polukonova NV, Manaenkova EV, Pankratova $\mathrm{LE}$, Kurchatova MN, et al. Antituberculous in vitro activity of helichrýsum arenárium extract. Eksperimental'naya i Klinicheskaya Farmakologiy 2015; 78(2): 30-33. Russian. https://elibrary.ru/item.asp?id=23070059.

14. Navolokin NA, Skvortsova VV, Polukonova NV, Manaenkova EV, Pankratova LE, Kurchatova MN, et al. Antituberculous in vitro activity of Gratiola officinalis extract. Eksperimental'naya $i$ Klinicheskaya Farmakologiya 2015; 78(4): 10-13. Russian. https://elibrary.ru/item.asp?id=23385865.

15. International guiding principles for biomedical research involving animals. CIOMS-ICLAS,

2012. https://grants.nih.gov/grants/olaw/Guiding_Principles_2012.pdf.

16. Hematology stains of blood and bone marrow: panoptic methods and methods for diagnostic testing of leukemia and MDS. Darmstadt, Germany: Merck KGaA, 2013; 57 p.

17. Acton AQ. Eosinophilia: New insights for the healthcare professional: 2013 Edition. Atlanta, Georgia: Scholarly Editions, 2013; 42 p.

18. Progress in Immunology VI: Sixth International Congress of Immunology. B. Cinader, R.G. Miller, eds. Elsevier Inc., 1986.

19. Ferreira JFS, Luthria DL, Sasaki $T$, Heyerick A. Flavonoids from Artemisia annua L. as antioxidants and their potential synergism with Artemisinin against malaria and cancer. Molecules 2010; 15(5): 31353170. https://dx.doi.org/10.3390/molecules15053135.

20. Kao TH, Huang RFS, Chen BH. Antiproliferation of hepatoma cell and progression of cell cycle as affected by isoflavone extracts from Soybean cake. Int J Mol Sci 2007; 8(11): 1095-1110. https://dx.doi.org/10.3390/i8111092. 
21. Chockalingam V, Kadali SS, Gnanasambantham P. Antiproliferative and antioxidant activity of Aegle marmelos (Linn.) leaves in Dalton's Lymphoma Ascites transplanted mice. Indian J Pharmacol 2012; 44(2): 225-229. https://dx.doi.org/10.4103/0253-7613.93854.

22. Kumarappan CT, Mandal SC. Antitumor activity of polyphenolic extract of ichnocarpus frutescens. Exp Oncol 2007; 29(2): 94-101. https://www.ncbi.nlm.nih.gov/pubmed/17704739.

\section{Authors:}

Nikita A. Navolokin - MD, Assistant, Department of Pathological Anatomy, Saratov State Medical University n.a. V.I. Razumovsky, Saratov, Russia. http://orcid.org/0000-0001-7876-9758.

Dmitry A. Mudrak - 6-year student, Saratov State Medical University n.a. V.I. Razumovsky, Saratov, Russia. http://orcid.org/0000-0001-7399-9204. Alla B. Bucharskaya - PhD, Head of the Centre of Collective Use, Research Institute of Fundamental and Clinical Uronephrology, Saratov State Medical University n.a. V.I. Razumovsky, Saratov, Russia. http://orcid.org/0000-0003-0503-6486.

Olga V. Matveeva - PhD, Researcher, Scientific Research Institute of Fundamental and Clinical Urology and Nephrology, Saratov State Medical University n.a. V.I. Razumovsky, Saratov, Russia. http://orcid.org/00000002-3536-2744.

Sergey A. Tychina - 6-year student, Saratov State Medical University n.a. V.I. Razumovsky, Saratov, Russia. http://orcid.org/0000-0001-7409-0676. Natalya V. Polukonova - DSc, Associate Professor, Department of General Biology Botany and Pharmacognosy, Saratov State Medical University n.a. V.I. Razumovsky, Saratov, Russia. http://orcid.org/0000-0001-9228-6808. Galina N. Maslyakova - MD, DSc, Professor, Head of the Department of Pathological Anatomy, Saratov State Medical University n.a. V.I. Razumovsky, Saratov, Russia. http://orcid.org/0000-0001-8834-1536. 